Interactive comment on "A Conceptual Framework for Integration Development of GSFLOW Model: Concerns and Issues Identified and Addressed for Model Development Efficiency" by Chao Chen et

al.

Kerkweg

kerkweg@uni-bonn.de

Received and published: 18 December 2018

Dear authors,

In my role as Executive editor of GMD, I would like to bring to your attention our Editorial version 1.1:

http://www.geosci-model-dev.net/8/3487/2015/gmd-8-3487-2015.html

This highlights some requirements of papers published in GMD, which is also available 
on the GMD website in the 'Manuscript Types' section:

http://www.geoscientific-model-development.net/submission/manuscript_types.html

In particular, please note that for your paper, the following requirements have not been met in the Discussions paper:

- "The main paper must give the model name and version number (or other unique identifier) in the title."

- "All papers must include a section, at the end of the paper, entitled 'Code availability'. Here, either instructions for obtaining the code, or the reasons why the code is not available should be clearly stated. It is preferred for the code to be uploaded as a supplement or to be made available at a data repository with an associated DOI (digital object identifier) for the exact model version described in the paper. Alternatively, for established models, there may be an existing means of accessing the code through a particular system. In this case, there must exist a means of permanently accessing the precise model version described in the paper. In some cases, authors may prefer to put models on their own website, or to act as a point of contact for obtaining the code. Given the impermanence of websites and email addresses, this is not encouraged, and authors should consider improving the availability with a more permanent arrangement. After the paper is accepted the model archive should be updated to include a link to the GMD paper."

Thus add the version number of GSFLOW to the title of your manuscript.

GMD is encouraging authors to provide a persistent access to the exact version of the source code used for the model version presented in the paper. As explained in https://www.geoscientific-model-development.net/about/manuscript_types.html the preferred reference to this release is through the use of a DOI which then can be cited

Printer-friendly version

Discussion paper 
in the paper. In case your institution does not provide the possibility to make electronic data accessible through a DOI you may consider other providers (eg. zenodo.org of CERN) to create a DOI. Please note that in the code accessibility section you can still point the reader to the repository for the newest version even if you use a DOI for the relevant releases.

Yours,

\section{Astrid Kerkweg}

Interactive comment on Geosci. Model Dev. Discuss., https://doi.org/10.5194/gmd-2018-268, 2018. 